\title{
Evaluation of Comparative Anti-arthritic Activity of Traditionally Well Documented Medicinal Plants in Rats
}

\author{
R. K. GAUTAM* ${ }^{*}$ S. SHARMA ${ }^{1}$, K. SHARMA² AND S. GOYAL ${ }^{3}$ \\ Department of Pharmacology, M. M. School of Pharmacy, Maharishi Markandeshwar University, Sadopur-Ambala-134007, \\ Haryana, ${ }^{1}$ NMIMS, School of Pharmacy \& Technology Management, Shirpur-425405, Maharashtra, ${ }^{2}$ Department of \\ Pharmacology, Bhupal Nobles' Institute of Pharmaceutical Sciences, Udaipur-313001, Rajasthan; ${ }^{3} \mathrm{~B}$. R. Nahata College of \\ Pharmacy, Mandsaur University, Mandsaur-458001, Madhya Pradesh, India
}

Gautam et al.: Comparative anti-arthritic evaluation of traditional medicinal plants

\begin{abstract}
The aim of our study is to evaluate comparative assessment of well documented medicinal plants. Ethanolic extract of Pongamia pinnata, Salvadora persica, Asparagus racemosus and methanolic extract of Punica granatum were prepared by continuous hot extraction method and their preliminary phytochemical screening was performed. Animals were separated into different groups and each group contains six animals. The ethanolic and methanolic extracts were administered in a dose of 200 and $400 \mathrm{mg} / \mathrm{kg}$. Arthritis was induced by FCA in Wistar albino rats and various parameters related to arthritis i.e. paw volume, arthritic score, body weight, joint diameter were recorded. A significant increase in paw volume, arthritic score, joint diameter and decrease in body weight was observed in arthritic control rats compared to normal control. Methanolic extract of Punica granatum significantly decreased the paw volume, arthritic score, and joint diameter and increased the body weight when compared to arthritic control. All the selected medicinal plants showed significant activity in arthritic rats however, methanolic extract of Punica granatum showed highly significant activity as compared to other plants. Methanolic extract showed the presence of flavonoids, alkaloids, terpanoids, glycosides, and phenolic compounds. The anti-arthritic activity of plant may be due to presence of aforementioned phytocomponds.
\end{abstract}

Key words: Anti-arthritic activity, ethanolic extracts, Asparagus racemosus, Salvadora persica, Pongamia pinnata, Punica granatum

Clinically, Rheumatoid arthritis (RA) is characterized by Polyarthritic, swelling and, in many cases, manifests extra-articular association. In the early step of the disease, typical signs and symptoms are swelling and pain of the proximal interphalangeal and metacarpophalangeal joints. In count, RA can influence other systems of the body, and this may variety from rheumatoid nodules to life-threatening vacuities ${ }^{[1]}$. It is anticipated that the disease is triggered by unknown antigens of infectious origins which when accessible to immune cells in the joint tissue initiate an event that is followed by the stimulation of an immune response, resulting in inflammation in the coating of the joints. RA mainly represents a distinctive T-cell mediated disease $^{[2,3]}$.

In ancient texts, more than 500 plants have been mentioned in traditional reports in the arthritis treatment; however only some plants have been investigated scientifically. Pongamia pinnata (Linn.) Pierre, Salvadora persica Linn., Asparagus racemosus

*Address for correspondence

E-mail: rupeshgautammmu@gmail.com

September-October 2020
Willd, and Punica granatum Linn are traditionally reported medicinal plants used in chronic inflammatory conditions $^{[4,5]}$. Anti-arthritic activity of these plants still remain to explore so in the proposed research work, on the basis of traditional claim, an attempt was made to explore anti-arthritic evaluation of the selected medicinal plants.

\section{MATERIAL AND METHODS}

Procurement, collection and authentication of plants:

The dried and processed Pongamia pinnata seeds, dried roots of Asparagus racemosus and fresh Punica

This is an open access article distributed under the terms of the Creative Commons Attribution-NonCommercial-ShareAlike 3.0 License, which allows others to remix, tweak, and build upon the work non-commercially, as long as the author is credited and the new creations are licensed under the identical terms

Accepted 10 October 2020

Revised 07 October 2020

Received 28 April 2020 Indian J Pharm Sci 2020;82(5):791-796 
granatum fruits were procured from local vendors of Udaipur, India while of Salvadora persica's fresh leaves were collected from Jaipur-India.

The seeds of $P$. pinnata, leaves of $S$. persica and roots of $A$. racemosus were identified taxonomically and authenticated at University of Rajasthan, Jaipur-India. Each plant part's voucher specimen was kept at the department with the specific voucher no. which is as RUBL21095, RUBL21076, RUBL21104, respectively. The fresh sample $P$. granatum fruit was taxonomically identified and authenticated at Horticulture Department, Rajasthan College of Agriculture, Udaipur-India.

\section{Extraction of all selected plants:}

The powder form of dried $P$. pinnata seeds, $S$. persica leaves, $A$. racemosus roots and $P$. granatum rind were prepared mechanically by using mesh sieve. Hot percolation method has been used to carry out the extraction. The powder of $P$. pinnata, S. persica and $A$. racemosus parts (250 g each) were treated with $90 \%$ ethanol. The filtrate of the various extracts was dried and get concentrated. By the same method, $P$. granatum $(250 \mathrm{~g})$ was extracted using methanol as a solvent. For $P$. pinnata, petroleum ether $\left(40-60^{\circ}\right)$ was used to remove all the fat soluble components and further extracted by using ethanol. The percentage yields of all the extracts were determined. The extract was dried to get concentrated and percentage yields of all the extracts were determined. All the extracts were also screened for the presence of various active phytoconstituents i.e. alkaloids, flavonoids, terpenoids and others.

\section{Animals:}

Healthy Wistar albino rats (150-200 g) were used throughout the study and the rats were maintained on standard diet and water ad libitum. Animals were well observed for any contamination and those showing signs of infection were excluded and replaced. All animal study were permitted by the IAEC (Institutional Animal Ethical Committee) (approval no. 192/PhD/2012/IAEC/BRNCP/12-13/Mandsaur). The rats were randomly distributed into eleven groups and each group contains six animals. CPCSEA guidelines were adhered during maintenance and experiments.

\section{Acute toxicity studies:}

According to OECD guidelines 423, toxicity studies were performed for the ethanolic and methanolic extracts. Extract of all plants were administered in dose of $2000 \mathrm{mg} / \mathrm{kg}$ p.o. The rats were observed for $24 \mathrm{~h}$ for any signs of various acute and short term toxicological symptoms i.e. convulsion, diarrhoea, coma, respiratory depression, salivation and perspiration ${ }^{[6]}$.

\section{Freund's complete adjuvant (FCA) induced arthritis in rats:}

For the evaluation of anti-arthritic activity of ethanolic extract of both plants, the animals were separated in different groups each contain six animals. The treatment schedule was as follows.

Group I- Normal control. Group II- Disease (arthritic) control (FCA induced arthritis) Group III- Arthritic rats+Dexamethasone in a dose of $5 \mathrm{mg} / \mathrm{kg}$. Group IVArthritic rats+ethanolic extract of $P$. pinnata (PPEE) seeds in a dose of $200 \mathrm{mg} / \mathrm{kg}$. Group V- Arthritic rats+ethanolic extract of $P$. pinnata (PPEE) seeds in a dose of $400 \mathrm{mg} / \mathrm{kg}$. Group VI- Arthritic rats+ethanolic extract of $S$. persica (SPEE) leaves in a dose of $200 \mathrm{mg} / \mathrm{kg}$. Group VII- Arthritic rats+ethanolic extract of $S$. persica (SPEE) leaves in a dose of $400 \mathrm{mg} / \mathrm{kg}$. Group VIII-Arthritic rats+ethanolic extract of A. racemosus (AREE) root in a dose of $400 \mathrm{mg} / \mathrm{kg}$. Group IX- Arthritic rats+ethanolic extract of $A$. racemosus (AREE) root in a dose of $400 \mathrm{mg} / \mathrm{kg}$. Group X-Arthritic rats + methanolic extract of P. granatum (PGME) rind in a dose of $400 \mathrm{mg} /$ kg. Group XI- Arthritic rats+methanolic extract of P. granatum (PGME) rind in a dose of $400 \mathrm{mg} / \mathrm{kg}$.

In order to induce experimental arthritis, $0.1 \mathrm{ml}$ of FCA was injected into sub-plantar region of left hind paw of each rat on $\mathrm{d} 1^{\text {st }}$. Dosing of all the animals groups was started from $\mathrm{d} 12^{\text {th }}$ once in a day p.o., after induction of arthritis, Anti-arthritic activity of extracts were evaluated by biophysical parameters such as arthritic score, body weight, paw volume and joint diameter ${ }^{[7,8]}$.

\section{Arthritic score:}

Different set illustration criteria was monitored according to methods followed by Paval et al. ${ }^{[9]}$.

\section{Paw volume:}

The volumes of left hind paw at different days by Plethysmometer. This parameter has been carried according to methods followed by Cain et al. ${ }^{[10]}$.

\section{Paw thickness (Joint diameter):}

Joint diameter was calculated by using screw gauge according to methods followed by Barbier et al. ${ }^{[11]}$. 


\section{Statistical analysis:}

All the results were expressed as mean \pm S.E.M. Statistical comparisons were made between treated groups and arthritic control groups. One-way ANOVA (Dunnett's test) has been used to analyze the data. Graph Pad Prism 5.0 version was used for this test. The values of $p<0.05$ were considered statistically significant.

\section{RESULT AND DISCUSSION}

All the extracts did not exhibit any toxicity symptoms or mortality when administered orally at dose of $2000 \mathrm{mg} / \mathrm{kg}$ in animals. Hence, 200 and $400 \mathrm{mg} / \mathrm{kg}$ were selected as therapeutic dose.

Animals treated with dexamethasone $5 \mathrm{mg} / \mathrm{kg}$ (standard drug) showed significant decrease in arthritic score $(p<0.01)$ from $d 14$ onward till the end of the study as compared to arthritic rats. Treatment with PPEE (200 and $400 \mathrm{mg} / \mathrm{kg}$ ) showed significant and dose dependant decrease in arthritic score $(\mathrm{p}<0.05$ and $\mathrm{p}<0.01)$ from $\mathrm{d} 14$ to 28 as compared to arthritic rats. SPEE (200 and $400 \mathrm{mg} / \mathrm{kg}$ ) showed significant decrease $(p<0.05$ and $p<0.01)$ from $d 21$ to 28 . AREE at $200 \mathrm{mg} / \mathrm{kg}$ showed significant decrease $(\mathrm{p}<0.05)$ d 21 to 28 while at $400 \mathrm{mg} / \mathrm{kg}$ showed significant decreased $(\mathrm{p}<0.05$ and $\mathrm{p}<0.01)$ from $\mathrm{d} 14$ to 28 . PGME $(200$ and $400 \mathrm{mg} / \mathrm{kg}$ ) showed significant decrease $(\mathrm{p}<0.05, \mathrm{p}<0.01$ and $\mathrm{p}<0.001)$ from $\mathrm{d} 14$ to 28 . On comparison, the effect of PGME on body weight was found to be more than PPEE, SPEE and AREE. The results are summarized in Table 1.

The body weight was significantly decreased $(p<0.01$ and $p<0.001$ ) from $d 14$ to till the end of the study in arthritic rats as compared to normal rats. Rats treated with dexamethasone $5 \mathrm{mg} / \mathrm{kg}$ (standard drug) showed significant increase in body weight $(\mathrm{p}<0.05$ and $\mathrm{p}<0.001$ ) from $\mathrm{d} 14$ as compared to arthritic rats. PPEE at $200 \mathrm{mg} / \mathrm{kg}$ showed significant increase in body weight $(\mathrm{p}<0.01)$ at $\mathrm{d} 28$ while at $400 \mathrm{mg} / \mathrm{kg}$ showed significant increase $(p<0.05$ and $p<0.001)$ from $d 14$ to 28 as comparable to arthritic rats. SPEE and AREE at $200 \mathrm{mg} / \mathrm{kg}$ showed significant increase $(\mathrm{p}<0.05)$ while both at $400 \mathrm{mg} / \mathrm{kg}$ showed significant increase $(\mathrm{p}<0.01)$ at $\mathrm{d} 28$. PGME (200 and $400 \mathrm{mg} / \mathrm{kg}$ ) showed significant increase $(p<0.01$ and $p<0.001)$ from $d 14$ to 28 . On comparison, the effect of PGME on body weight was found to be more than PPEE, SPEE and AREE. The results are summarized in Table 2.

The paw volume was significantly increased $(p<0.01$ and $p<0.001$ ) from $d 14$ to till the end of the study in arthritic rats as compared to normal rats. Rats treated with dexamethasone $5 \mathrm{mg} / \mathrm{kg}$ (standard drug) showed significant decrease in paw volume $(p<0.05, p<0.01$ and $\mathrm{p}<0.001$ ) from $\mathrm{d} 14$ as compared to arthritic rats. Treatment with PPEE at $200 \mathrm{mg} / \mathrm{kg}$ produced significant and dose dependant decrease in paw volume $(\mathrm{p}<0.05$ and $\mathrm{p}<0.01)$ from $\mathrm{d} 21$ to 28 while at $400 \mathrm{mg} / \mathrm{kg}$ showed significant decrease $(\mathrm{p}<0.05$ and $\mathrm{p}<0.01)$ from $\mathrm{d} 14$ to 28 as compared to arthritic rats. SPEE (200 and $400 \mathrm{mg} / \mathrm{kg}$ ) and AREE (200 and $400 \mathrm{mg} / \mathrm{kg}$ ) showed significant decrease $(\mathrm{p}<0.05$ and $\mathrm{p}<0.01$ ) from d 21 to 28 . PGME (200 and $400 \mathrm{mg} / \mathrm{kg}$ ) showed significantdecrease $(\mathrm{p}<0.01$ and $\mathrm{p}<0.001)$ from $\mathrm{d}$ 14 to 28 . On comparison, it was observed that the effect of PGME on paw volume was found to be more than PPEE, SPEE and AREE. The results are summarized in Table 3.

The joint diameter was significantly increased $(\mathrm{p}<0.01$ and $\mathrm{p}<0.001)$ from $\mathrm{d} 14$ to till the end of the study in

TABLE 1: COMPARATIVE EFFECT OF PPEE, SPEE, AREE AND PGME ON ARTHRITIC SCORE

\begin{tabular}{lccccc}
\hline Treatment & 0 day & $7^{\text {th }}$ day & $14^{\text {th }}$ day & $21^{\text {st }}$ day & $28^{\text {th }}$ day \\
\hline Normal Rats & - & - & - & - \\
Arthritic Rats & - & $3.31 \pm 0.12$ & $3.56 \pm 0.21$ & $3.97 \pm 0.00$ & $4.12 \pm 0.05$ \\
Dexa $(5 \mathrm{mg} / \mathrm{kg})$ & - & $3.47 \pm 0.21$ & $3.27 \pm 0.08^{* *}$ & $2.87 \pm 0.11^{* *}$ & $2.57 \pm 0.42^{* *}$ \\
PPEE (200 mg/kg) & - & $3.82 \pm 0.04$ & $3.62 \pm 0.24^{*}$ & $3.47 \pm 0.08^{*}$ & $3.32 \pm 0.18^{* *}$ \\
PPEE (400 mg/kg) & - & $3.58 \pm 0.19$ & $3.39 \pm 0.07^{*}$ & $3.19 \pm 0.32^{* *}$ & $2.92 \pm 0.14^{* *}$ \\
SPEE (200mg/kg) & - & $3.12 \pm 0.12$ & $3.01 \pm 0.19$ & $2.92 \pm 0.03^{*}$ & $2.86 \pm 0.26^{*}$ \\
SPEE (400mg/kg) & - & $3.18 \pm 0.27$ & $3.04 \pm 0.00$ & $2.86 \pm 0.19^{*}$ & $2.72 \pm 0.26^{* *}$ \\
AREE (200mg/kg) & - & $2.96 \pm 0.26$ & $2.82 \pm 0.18$ & $2.68 \pm 0.17^{*}$ & $2.51 \pm 0.13^{*}$ \\
AREE (400mg/kg) & - & $2.88 \pm 0.26$ & $2.69 \pm 0.17^{*}$ & $2.48 \pm 0.41^{*}$ & $2.27 \pm 0.32^{* *}$ \\
PGME (200mg/kg) & - & $3.87 \pm 0.12$ & $3.52 \pm 0.16^{*}$ & $3.26 \pm 0.27^{* *}$ & $2.99 \pm 0.36^{* * *}$ \\
PGME (400mg/kg) & - & $3.73 \pm 0.06$ & $3.19 \pm 0.42^{* *}$ & $2.62 \pm 0.16^{* * *}$ & $2.12 \pm 0.13^{* * *}$ \\
\hline
\end{tabular}

Data were expressed in mean \pm SEM and analyzed by ANOVA followed by Dunnett's test. Arthritic group was compared with normal while all treated group were compared with arthritic group. " $p<0.05$ (significant), " $p<0.01$ (moderately significant), "*** $p<0.001$ (highly significant). PPEE- Ethanolic extract of P. pinnata; SPEE- Ethanolic extract of S. persica; AREE - Ethanolic extract of $A$. racemosus; PGME -Methanolic extract of $P$. granatum. 
arthritic rats as compared to normal rats. Rats treated with dexamethasone $5 \mathrm{mg} / \mathrm{kg}$ (standard drug) showed significant decrease in joint diameter $(p<0.05, p<0.01$ and $p<0.001$ ) from $d 14$ onward till the end of the study as compared to arthritic rats. Treatment with PPEE (200 and $400 \mathrm{mg} / \mathrm{kg}$ ) showed significant decrease $(\mathrm{p}<0.01$ and $\mathrm{p}<0.001)$ as compared to arthritic rats. SPEE (200 and $400 \mathrm{mg} / \mathrm{kg}$ ) and AREE (200 and $400 \mathrm{mg} /$ $\mathrm{kg})$ showed significant decrease $(\mathrm{p}<0.05$ and $\mathrm{p}<0.01)$ from d 21 to 28. PGME (200 and $400 \mathrm{mg} / \mathrm{kg}$ ) showed significant decrease $(\mathrm{p}<0.01$ and $\mathrm{p}<0.001)$ from $\mathrm{d}$ 14 to 28. On comparison, it was found that the effect of PGME on joint diameter was found to be more than PPEE, SPEE and AREE. The results are summarized in Table 4.

Various animal models of inflammation are used widely in research on pathogenesis of inflammatory arthritis. Freund's complete induced arthritis (FCA) or Adjuvantinduced arthritis in rat's model was selected for the investigation because this is a common and extensively used animal model for the studies of rheumatoid arthritis, an autoimmune disease, and inflammation ${ }^{[12]}$. FCA induced model is a well-liked and chronic model in which the pathological and clinical changes are closely similar with those seen in human rheumatoid $\operatorname{arthritis}^{[13,14]}$. This model is a useful tool to study the pathophysiology of rheumatoid arthritis in rats, especially because this experimental model and the human disease have common signs and symptoms ${ }^{[15,16]}$.

Thus, in the present exploration, an effort was taken to evaluate the anti-arthritic effect of Pongamia pinnata, Salvadora persica, Asparagus racemosus and Punica granatum by in-vivo model, to compare and identify the most active plant extract responsible for activity. In FCA induced arthritis, arthritis score is index of inflammation of the joint after immunization ${ }^{[17,18]}$. In preliminary study, PPEE, SPEE, AREE and PGME

TABLE 2: COMPARATIVE EFFECT OF PPEE, SPEE, AREE AND PGME ON BODY WEIGHT (GM)

\begin{tabular}{|c|c|c|c|}
\hline Treatment & 0 day & $14^{\text {th }}$ day & $28^{\text {th }}$ day \\
\hline Normal Rats & $181.3 \pm 1.45$ & $185.5 \pm 1.23$ & $186.8 \pm 0.56$ \\
\hline Arthritic Rats & $190.2 \pm 0.94$ & $173.0 \pm 0.73^{* *}$ & $135.7 \pm 0.71^{* * *}$ \\
\hline Dexa (5 mg/kg) & $197.8 \pm 0.94$ & $183.0 \pm 1.21^{*}$ & $205 \pm 0.71^{* * *}$ \\
\hline PPEE $(200 \mathrm{mg} / \mathrm{kg})$ & $186.5 \pm 0.57$ & $182.5 \pm 1.73$ & $212.3 \pm 1.03^{* *}$ \\
\hline PPEE (400 mg/kg) & $186.8 \pm 0.61$ & $185.7 \pm 0.93^{*}$ & $225.7 \pm 1.59^{* * * *}$ \\
\hline SPEE (200mg/kg) & $182.0 \pm 0.56$ & $181.0 \pm 1.75$ & $195.2 \pm 2.53^{*}$ \\
\hline SPEE (400mg/kg) & $184.0 \pm 0.73$ & $182.3 \pm 1.41$ & $204.2 \pm 1.62^{* *}$ \\
\hline AREE $(200 \mathrm{mg} / \mathrm{kg})$ & $186.8 \pm 0.69$ & $184.5 \pm 1.53$ & $203.5 \pm 1.74^{*}$ \\
\hline AREE (400mg/kg) & $186.3 \pm 0.57$ & $183.3 \pm 1.60$ & $208.5 \pm 1.22^{* *}$ \\
\hline PGME (200mg/kg) & $180.4 \pm 0.63$ & $176.5 \pm 0.61^{* *}$ & $225.5 \pm 0.47^{* * *}$ \\
\hline PGME (400mg/kg) & $182.9 \pm 0.52$ & $179.6 \pm 1.95^{* *}$ & $239.3 \pm 1.45^{* * *}$ \\
\hline
\end{tabular}

Data were expressed in mean \pm SEM and analyzed by ANOVA followed by Dunnett's test. Arthritic group was compared with normal while all treated group were compared with arthritic group. " $p<0.05$ (significant), " $p<0.01$ (moderately significant), " $p<0.001$ (highly significant). PPEE- Ethanolic extract of $P$. pinnata; SPEE- Ethanolic extract of S. persica; AREE - Ethanolic extract of $A$. racemosus; PGME - Methanolic extract of $P$. granatum

TABLE 3: COMPARATIVE EFFECT OF PPEE, SPEE, AREE AND PGME ON PAW VOLUME (ML)

\begin{tabular}{lccccc}
\hline Treatment & 0 day & $7^{\text {th }}$ day & $14^{\text {th }}$ day & $21^{\text {st }}$ day & $28^{\text {th }}$ day \\
\hline Normal Rats & $0.821 \pm 0.14$ & $0.822 \pm 0.01$ & $0.822 \pm 0.11$ & $0.823 \pm 0.12$ & $0.823 \pm 0.17$ \\
Arthritic Rats & $0.828 \pm 0.19$ & $1.486 \pm 0.07$ & $1.583 \pm 0.16^{* *}$ & $1.822 \pm 0.12^{* * *}$ & $2.888 \pm 0.05^{* * *}$ \\
Dexa (5 mg/kg) & $0.829 \pm 0.11$ & $1.479 \pm 0.13$ & $1.346 \pm 0.08^{*}$ & $1.044 \pm 0.22^{* *}$ & $0.846 \pm 0.57^{* * *}$ \\
PPEE (200mg/kg) & $0.824 \pm 0.09$ & $1.491 \pm 0.08$ & $1.411 \pm 0.05$ & $1.322 \pm 0.12^{*}$ & $1.227 \pm 0.36^{* *}$ \\
PPEE (400 mg/kg) & $0.822 \pm 0.17$ & $1.482 \pm 0.11$ & $1.392 \pm 0.03^{*}$ & $1.298 \pm 0.1^{* *}$ & $1.209 \pm 0.0^{* *}$ \\
SPEE (200mg/kg) & $0.823 \pm 0.02$ & $1.487 \pm 0.05$ & $1.463 \pm 0.03$ & $1.392 \pm 0.09^{*}$ & $1.346 \pm 0.45^{*}$ \\
SPEE (400mg/kg) & $0.821 \pm 0.23$ & $1.489 \pm 0.07$ & $1.447 \pm 0.15$ & $1.379 \pm 0.09^{*}$ & $1.312 \pm 0.37^{* *}$ \\
AREE (200mg/kg) & $0.826 \pm 0.34$ & $1.484 \pm 0.01$ & $1.456 \pm 0.09$ & $1.381 \pm 0.05^{*}$ & $1.329 \pm 0.43^{*}$ \\
AREE (400mg/kg) & $0.824 \pm 0.0$ & $1.481 \pm 0.11$ & $1.434 \pm 0.12$ & $1.359 \pm 0.23^{*}$ & $1.303 \pm 0.36^{* *}$ \\
PGME (200mg/kg) & $0.832 \pm 0.19$ & $1.496 \pm 0.05$ & $1.315 \pm 0.21^{* *}$ & $0.997 \pm 0.14^{* * *}$ & $0.859 \pm 0.06^{* * *}$ \\
PGME (400mg/kg) & $0.826 \pm 0.21$ & $1.485 \pm 0.19$ & $1.286 \pm 0.32^{* * *}$ & $0.944 \pm 0.13^{* * *}$ & $0.836 \pm 0.12^{* * *}$ \\
\hline Data Werexpressed
\end{tabular}

Data were expressed in mean \pm SEM and analyzed by ANOVA followed by Dunnett's test. Arthritic group was compared with normal while all treated group were compared with arthritic group. " $p<0.05$ (significant), $" \mathrm{p}<<0.01$ (moderately significant), "*** $p<0.001$ (highly significant). PPEE- Ethanolic extract of P. pinnata; SPEE- Ethanolic extract of S. persica; AREE - Ethanolic extract of A. racemosus; PGME - Methanolic extract of $P$. granatum 
TABLE 4: COMPARATIVE EFFECT OF PPEE, SPEE, AREE AND PGME ON JOINT DIAMETER (MM)

\begin{tabular}{lccccc}
\hline Treatment & $0 \mathrm{~d}$ & $7^{\text {th }} \mathrm{d}$ & $14^{\text {th }} \mathrm{d}$ & $21^{\text {st }} \mathrm{d}$ & $28^{\text {th }} \mathrm{d}$ \\
\hline Normal Rats & $2.18 \pm 0.02$ & $2.20 \pm 0.01$ & $2.2 \pm 0.01$ & $2.19 \pm 0.01$ & $2.28 \pm 0.06$ \\
Arthritic Rats & $2.11 \pm 0.23$ & $2.35 \pm 0.01$ & $2.45 \pm 0.15^{* *}$ & $2.96 \pm 0.01^{* * *}$ & $3.28 \pm 0.03^{* * *}$ \\
Dexa (5 mg/kg) & $1.81 \pm 0.12$ & $1.92 \pm 0.20$ & $1.82 \pm 0.22^{*}$ & $1.38 \pm 0.35^{* *}$ & $1.01 \pm 0.07^{* * *}$ \\
PPEE (200mg/kg) & $1.98 \pm 0.14$ & $2.18 \pm 0.11$ & $1.94 \pm 0.25$ & $1.76 \pm 0.31^{* * *}$ & $1.55 \pm 0.41^{* *}$ \\
PPEE (400mg/kg) & $1.23 \pm 0.23$ & $2.37 \pm 0.05$ & $2.15 \pm 0.16$ & $1.82 \pm 0.28^{* * *}$ & $1.45 \pm 0.1^{* * *}$ \\
SPEE (200mg/kg) & $1.84 \pm 0.34$ & $1.97 \pm 0.19$ & $1.84 \pm 0.29$ & $1.66 \pm 0.42^{*}$ & $1.59 \pm 0.55^{*}$ \\
SPEE (400mg/kg) & $1.97 \pm 0.05$ & $2.13 \pm 0.11$ & $1.85 \pm 0.3$ & $1.65 \pm 0.43^{*}$ & $1.47 \pm 0.42^{* *}$ \\
AREE (200mg/kg) & $2.23 \pm 0.13$ & $2.37 \pm 0.54$ & $2.2 \pm 0.12$ & $1.95 \pm 0.32^{*}$ & $1.77 \pm 0.50^{*}$ \\
AREE (400mg/kg) & $2.18 \pm 0.17$ & $2.26 \pm 0.13$ & $2.12 \pm 0.18$ & $1.87 \pm 0.27^{* *}$ & $1.62 \pm 0.38^{* *}$ \\
PGME (200mg/kg) & $2.11 \pm 0.18$ & $2.16 \pm 0.09$ & $1.77 \pm 0.23^{* *}$ & $1.56 \pm 0.37^{* *}$ & $1.36 \pm 0.05^{* * *}$ \\
PGME (400mg/kg) & $2.14 \pm 0.21$ & $2.2 \pm 0.19$ & $1.67 \pm 0.23^{* *}$ & $1.17 \pm 0.09^{* * *}$ & $0.77 \pm 0.08^{* * *}$ \\
\hline
\end{tabular}

Data were expressed in mean \pm SEM and analyzed by ANOVA followed by Dunnett's test. Arthritic group was compared with normal while all treated group were compared with arthritic group. " $p<0.05$ (significant), "* $p<0.01$ (moderately significant), " $p<0.001$ (highly significant). PPEE- Ethanolic extract of $P$. pinnata; SPEE- Ethanolic extract of S. persica; AREE - Ethanolic extract of A. racemosus; PGME -Methanolic extract of $P$. granatum

exhibited significant reduction in the arthritic scores. PGME was potent in reducing the arthritic score.

Disease recovery and health status are indirectly related with body weight. Body weight, metabolism and food intake are affected by inflammation and immunity ${ }^{[19-21]}$. Rheumatoid arthritis (RA) is associated with loss of weight and lean body mass loss and known as rheumatoid cachexia. Rheumatoid cachexia is end result of cytokine-driven hyper metabolism and is means morbidity in RA. The loss of lean body mass is linked with decreased muscle strength, physical activity, and survival in performing daily living activities $^{[22-25]}$. In previous studies, it is reported that during inflammation body weight is decreased due to less absorption of nutrients through the intestine. The process of absorption normalizes by the treatment of anti-inflammatory drugs. In the present investigation, PPEE, SPEE, AREE and PGME were found to produce significant increase in body weight. PGME was most effective in increasing the body weight. The apparent abolition of the body weight of rats in the PGME treated group may involve better improvement of nutrients absorption in intestine and a suppression in the distress caused by the severity of the arthritis than other treated groups ${ }^{[13,21]}$. Better weight gain was bringing into being upon physical consideration of PGME treated rats. As suggested in previous studies the treatment of rheumatoid cachexia as it is observed due to pretreatment with PGME could be effective in minimizing risk of mortality.

Reduction in paw swelling is a parameter of measuring the anti-arthritic activity of numerous drugs ${ }^{[26]}$. This is one of the major factors and quite simple, sensitive and one of the quick methods in assessing the degree of inflammation and therapeutic efficacy of the anti- inflammatory and anti-arthritic drugs ${ }^{[9,27,28]}$. Here, it has been observed that PGME treated rats demonstrated a highly significant reduction in paw swelling (paw volume) when compared with PPEE, SPEE and AREE treated rats.

Significant increase in the paw thickness (joint diameter) after sub-plantar FCA administration demonstrates a condition similar to clinical arthritis. Pretreatment with all the four extracts produced a significant reduction in joint diameter. The most significant effect was with PGME again found to be most effective in reducing joint diameter. The reduction in paw thickness is considered to be reduction in release of mediators of inflammatory and it is an indicator of anti-inflammatory and antiarthritic action of any drug in FCA induced arthritis ${ }^{[17]}$.

The results observed in various studies performed in in-vitro and in-vivo confirm that Pongamia pinnata, Salvadora persica, Asparagus racemosus and Punica granatum contain certain active phytoconstituents which are responsible for anti-inflammatory and antiarthritic activity.

Phytochemical evaluation of ethanolic and methanolic plant extracts confirmed the presence of biologically active phytoconstituents, i.e. PPEE showed the presence of steroids, flavonoids, alkaloids, terpenoids, glycosides, saponins, tannins and phenolic compounds. In SPEE phytocompounds such as steroids, flavonoids, alkaloids, terpenoids and glycosides were present. Steroids and flavonoids were present in AREE. PGME showed the presence of steroids, flavonoids, terpenoids, glycosides, iridoid glycosides, tannins and phenolic compounds.

In-vivo study clearly demonstrated that PPEE, SPEE, AREE and PGME have anti-arthritic activity and 
presence of aforementioned phytocompounds in the extracts may be responsible for the anti-arthritic activity shown by these plant extracts.

The present study focuses on the authentication and scientific validation of traditional claims made about some medicinal plants as anti-arthritic agents. On the basis of comparative results of the in-vivo study, it could be concluded that all the selected medicinal plants have significant activity however; PGME has most significant anti-arthritic activity. Punica granatum may play a vital role in the treatment of rheumatoid arthritis and it might be a better herbal drug for the same.

\section{Conflict of interests:}

The authors declared no conflict of interest.

\section{REFERENCES}

1. Smolen JS, Steiner G. Therapeutic strategies for rheumatoid arthritis. Nat Rev Drug Discov 2003;2(6):473-88.

2. Gautam RK, Gupta G, Sharma S, Hatware K, Patil K, Sharma K, et al. Rosmarinic acid attenuates inflammation in experimentally induced arthritis in Wistar rats, using Freund's complete adjuvant. Int J Rheum Dis 2019;22(7):1247-54.

3. Nagy G, Clark JM, Buzás EI, Gorman CL, Cope AP. Nitric oxide, chronic inflammation and autoimmunity. Immunol Lett 2007;111(1):1-5.

4. Agrawal SS, Paridhavi M. Herbal Drugs Technology. Universities press (India) private limited 2007.

5. Gautam RK, Singh D, Nainwani R. Medicinal plants having anti-arthritic potential: A review. Int J Pharm Sci Rev Res 2013;19(1):96-102.

6. OECD 2001. OECD guideline for testing of chemicals: Acute Oral Toxicity - Acute Toxic Class Method. OECD Guidel. Test Chem 1-14.

7. Gautam RK, Sharma S, Sharma K, Gupta G. Evaluation of Antiarthritic Activity of Butanol Fraction of Punica granatum Linn. Rind extract against Freund's complete AdjuvantInduced Arthritis in Rats. J Environ Pathol Toxicol Oncol 2018;37(1):53-62.

8. Lin B, Zhao Y, Han P, Yue W, Ma X-Q, Rahman K, et al. Anti-arthritic activity of Xanthium strumarium L. extract on complete Freund's adjuvant induced arthritis in rats. J Ethnopharmacol 2014;155(1):248-55.

9. Paval J, Kaitheri S, Potu B, Govindan S, Kumar R, Narayanan $\mathrm{S}$, et al. Comparing the anti-arthritic activities of the plants Justicia gendarussa burm F. and Withania somnifera linn Int J Green Pharm 2009;3:281.

10. Cain CK, Francis JM, Plone MA, Emerich DF, Lindner MD. Pain-related disability and effects of chronic morphine in the adjuvant-induced arthritis model of chronic pain. Physiol Behav 1997;62:199-205.

11. Barbier A, Navarro J, Breliere JC, Roncucci R. Biochemical and clinical changes in rats with developing adjuvant arthritis. Agents Actions 1984;15:103-5.

12. Arulmozhi S, Mazumder PM, Sathiyanarayanan L, Ashok P.
Anti-arthritic and antioxidant activity of leaves of Alstonia scholaris Linn. R.Br. Eur J Integr Med 2011;3:e83-90.

13. Jalalpure SS, Mandavkar YD, Khalure PR, Shinde GS, Shelar PA, Shah AS. Antiarthritic activity of various extracts of Mesua ferrea Linn. seed. J Ethnopharmacol 2011;138(3):700-4.

14. Ward JR, Cloud RS. Comparative effect of antirheumatic drugs on adjuvant-induced polyarthritis in rats. J Pharmacol Exp Ther 1966;152:116-21.

15. Patel P, Patel D, Patel N. Experimental investigation of antirheumatoid activity of Pleurotus sajorcaju in adjuvant-induced arthritic rats. Chin J Nat Med 2012;10:269-74.

16. Pearson CM, Wood FD. Studies of arthritis and other lesions induced in rats by the injection of mycobacterial adjuvant. VII. Pathologic details of the arthritis and spondylitis. Am J Pathol 1963;42:73-95.

17. Patil MVK, Kandhare AD, Bhise SD. Anti-arthritic and antiinflammatory activity of Xanthium srtumarium L. ethanolic extract in Freund's complete adjuvant induced arthritis. Biomed. Aging Pathol 2012;2:6-15.

18. Yu Y, Xiong Z, Lv Y, Qian Y, Jiang S, Tian Y. In-vivo evaluation of early disease progression by X-ray phasecontrast imaging in the adjuvant-induced arthritic rat. Skeletal Radiol 2006;35(3):156-164.

19. Calvino B, Crepon-Bernard MO, Le Bars D. Parallel clinical and behavioural studies of adjuvant-induced arthritis in the rat: possible relationship with "chronic pain". Behav Brain Res. 1987;24:11-29.

20. Morton D, Griffiths P. Guidelines on the recognition of pain, distress and discomfort in experimental animals and an hypothesis for assessment. Vet Rec 1985;116(16):431-6.

21. Patil K, Suryavanshi J. Effect of Celastrus paniculatus Willd. seed on adjuvant induced arthritis in Rats. Pharmacogn Mag 2007;3(11):177-81.

22. Kyei S, Koffuor GA, Boampong JN. Antiarthritic effect of aqueous and ethanolic leaf extracts of Pistia stratiotes in adjuvant-induced arthritis in Sprague-Dawley rats. J Exp Pharmacol 2012;4:41-51.

23. Roubenoff R, Freeman LM, Smith DE, Abad LW, Dinarello CA, Kehayias JJ. Adjuvant arthritis as a model of inflammatory cachexia. Arthritis Rheum 1997;40(3):534-9.

24. Roubenoff R, Roubenoff RA, Cannon JG, Kehayias JJ, Zhuang $\mathrm{H}$, Dawson-Hughes B, et al. Rheumatoid cachexia: cytokinedriven hypermetabolism accompanying reduced body cell mass in chronic inflammation. J Clin Invest 1994;93(6):237986.

25. Roubenoff R, Rall LC. Humoral mediation of changing body composition during aging and chronic inflammation. Nutr Rev 1993;51:1-1.

26. Ekambaram S, Perumal SS, Subramanian V. Evaluation of antiarthritic activity of Strychnos potatorum Linn seeds in Freund's adjuvant induced arthritic rat model. BMC Complement. Altern Med 2010;10:56.

27. Begum VH, Sadique J. Long term effect of herbal drug Withania somnifera on adjuvant induced arthritis in rats. Indian J Exp Biol 1988;26:877-82.

28. Rajendran R, Krishnakumar E. Anti-Arthritic Activity of Premna serratifolia Linn., Wood against Adjuvant Induced Arthritis. Avicenna J Med Biotechnol 2010;2:101-6. 